\title{
Future First Responders can be as Young as Nine Years Old
}

\section{Kathleen E Jones*}

Invest in Nursing Nurse Educator Fellowship, University of North Carolina, Chapel Hill, North Carolina, USA

*Corresponding Author: Kathleen E Jones, Invest In Nursing Nurse Educator Fellowship, University of North Carolina, Chapel Hill, North Carolina, USA.
Received: July 09, 2021

Published: September 20, 2021

(C) All rights are reserved by Kathleen E

Jones.

\section{Abstract}

Violence is on the rise in America. Since the start of 2021, in the United States there have been 232 shootings, up from the 2013 number of 166 mass shootings, with around an astonishing 43,000 deaths by gun violence in 2020 per GunViolenceArchives.org. Much has been learned from each tragic event such as faster response time for medical help, learning how to instruct lay people in the community to help those injured on the scene, how to survive an active shooter event, and the need for the survivors to seek out mental health services in the afterward of such a horrific event. At one time the current practice revolved around combat care, then it transitioned to a very different practice, but it has once again returned to a military-based on-scene care. There has been the emergence of stressing this knowledge of skills by the Stop the Bleed (STB) campaign, which teaches lay people with no medical background, how to care for victims by calling 911, to identify the severity of the bleeding, to use of tourniquets, compression, packing of wounds, and reducing the risk of death. STB is a very successful program. However, when one looks back at the targets of vicious shootings, schools are a commonplace as 38 percent of shootings occur in schools. Currently, there is no education program for teenagers or children, yet they are the first ones at the scene and if they were equipped with knowledge, perhaps they could save lives. A presentation was done with teenagers in a North Carolina high school in Hickory successfully. Elementary school age children were then considered as a pilot for how young a responder could be. The sample size of four children ages six years-old to nine years-old were examined. The hypothesis answered is how young can a successful participant be for the Stop the Bleed education program? In conclusion, it is noted that children are underused in emergent situations and can be trained effectively with optimal long-term recollection of skills taught at nine years of age.

Keywords: Children; Teaching; Trauma Skills; Active Hemorrhage; Mass Casualty

\section{Introduction}

The STB campaign targets the adult learner but would if this were geared to the pediatric population, one ponders how many lives would have been saved at Sandy Hook, in Connecticut. It is known that the mortality following any shooting is related to time of provision of initial on-scene and definitive care. Studies show that a person shot with a serious wound can bleed out in less than six minutes, and an average dispatch of an ambulance will take up to 14 minutes, therefore demise is likely. How different this like- lihood would be if children were taught how to properly do this simple lifesaving skill.

One goal of stop the bleed campaign

One goal of STB is to educate the public on an understanding of the severity of the wounding pattern, opportunities for rescue, and incidence of a possibly preventable death is needed to achieve the hope of zero preventable deaths following a mass shooting trauma. 


\section{Literary Review}

It has been examined through the era of Columbine High School in Littleton, Colorado to the time of Sandy Hook Elementary School in Newtown, Connecticut how important a public lay person response is needed [6]. The idea of enhancing the emergency response to decrease fatalities during the waiting time due to hemorrhagic shock, was the gold standard but response times can vary, however, the best care is immediately rendered at the scene by those present [14]. Smith points to the life loss from the Pulse Night Club incident and how this care could have saved lives [14].

Rapid care, rapid evacuation as noted on the combat fields by the American military during the Iraq and Afghanistan wars [7], proved to be the most effective [1]. Butler [1] reintroduced the concept of tactical combat skills from 20 years ago with its aggressive use of tourniquets proved to save lives with minimal limb loss. Butler [1] identified as active shooter events, terrorist bombings, along with everyday traumas from vehicle accidents, this skillset had a real place, and the civilian layperson could learn to save lives if a formal education program was introduced. Stop the Bleed offered the means for this needed education for on-scene injury care as the program identified that within the first 24 hours after arriving to the hospital there is a significant loss of exsanguination [11].

Ross [10] warns it is not clear what type of education or the duration of instruction is needed to meet the requirement for successful hemorrhage control. Other concerns Ross pondered where would the willingness of laypersons to respond during a traumatic emergency remain in an event [10]. Ross did conclude that this short educational intervention can improve laypersons' effectiveness and reported willingness to use a tourniquet in an emergency event [10]. Zwislewski [17] notes that the STB campaign is not readily known in the layperson community, and its importance is not recognized, and for those who had the hands-on presentation versus the virtual instruction were more proficient in care delivery and more successful overall.

Lei [8] recognized that this program provided the participants with confidence and knowledge to help in preventing hemorrhagic death. Dhillon [2] stated the need for improvisation of tools would be needed with an element of creativity is needed because how likely would a layperson carry a tourniquet on their person.

Ramirez [9] and Guiesewite [3] agree that psychological first aid should be administered to participants who display post-trau- matic symptoms after the education. Guisewite [3] advises to have parents observe each child for the next month to determine any regression of behaviors, expected observation about one month, nightmares, eating and/ or sleeping changes, that may result from teaching. It is unlikely that a child of age six years or more will have a PTSD reaction from an education piece unless there was already a traumatic event in the child's past that would then possibly make this educational presentation a trigger of the past traumatic event. Instructions to observe the children for such issues were shared with the parents and support persons of each child [3].

The thought that remains is: who better to administer care in an elementary school event than a child who is already on the scene? This research done examines how young can a first responder be to successfully retain the skills to save another person's life?

\section{Design}

A standardized survey instrument was distributed to all children using a Likert scale of numbers with faces to determine each child's answer as 'yes' or 'no'. Parents were instructed to not give their children the answers but to only explain the question if needed. STB Control Basic (B-Con) class participants on 04/17/21 were in this pilot program. The instrument queried about the likelihood of applying skills, the child's feelings, and awareness of the addressed problem, and obtaining materials that could be used in their immediate environments as most of the typical equipment will likely not be available. A follow-up survey was administered one month later inquiring whether there were any issues of posttraumatic concern post-education.

\section{Setting}

Academic, rural location via Campbell University in Bouie's Creek, North Carolina.

\section{Participants}

The children are not healthcare trained and have no prior experience in this type of education. The mothers of the children gave verbal participation in the course and were present the entire duration of the class and hands-on skill demonstration. This was a pilot group of four children: two nine-year-old males, one sevenyear-old female, and a six-year-old female. None had identified or diagnosed learning or social disabilities, and the structure of the session included a playtime session before the class as a group. Questions by the children were answered, the more graphic bloody photos in the STB PowerPoint were removed, a questionnaire was 
completed by the children, and another play session was done after with snacks and juice given. All four children observed to be snacking, coloring, and socializing before and after nicely. Instructions for mothers and support persons were given to observe for post-traumatic concerns after the session. Follow-up checks on the children was done two-weeks, one month, and again at three months after to assess possible residual emotional adverse issues stemming from the education session.

\section{Results and Discussion}

Of these four participants ( $n=4)$, there were six questions asked via a survey before the educational presentation and another five questions asked post-teaching (See table 1 and 2). At the end of the pre-session survey, a short answer question was posed: why did you take this class today?

\begin{tabular}{|l|c|c|c|}
\hline Question & Answer & Answer & Answered \\
\hline $\begin{array}{l}\text { Do you watch the news } \\
\text { with your family? }\end{array}$ & Yes (2/4) & No (1/4) & $\begin{array}{c}\text { Sometimes } \\
(1 / 4)\end{array}$ \\
\hline $\begin{array}{l}\text { Do you think guns are } \\
\text { good or bad? }\end{array}$ & Good (1/4) & Bad (1/4) & - \\
\hline $\begin{array}{l}\text { Does your family have } \\
\text { guns in your home? }\end{array}$ & Yes (4/4) & No (0/4) & - \\
\hline $\begin{array}{l}\text { Do you think you will } \\
\text { help someone bleeding } \\
\text { when you learn this new } \\
\text { skill? }\end{array}$ & Yes (4/4) & No (0/4) & - \\
\hline Row Head & 789 & 789 & 789 \\
\hline
\end{tabular}

Table 1: Pre-session $n=4$.

Note: These are the results from the pre-session questions asked of the four children. Additional questions asked of the pilot group included: Why did you take this training?

Two answered: "my mother wanted me to do this" 6 y-o female and 9 y-o male.

One replied: "I think it is important to help people when they get hurt" 7 y-o female.

One replied: "I want to know that if something happened, that I could save someone" 9 y-o male.

\begin{tabular}{|l|c|c|c|}
\hline \multicolumn{1}{|c|}{ Question } & Answer & Answer & Answered \\
\hline $\begin{array}{l}\text { Do you think that this } \\
\text { special skill will be useful } \\
\text { to you? }\end{array}$ & Yes (4/4) & No (0/4) & - \\
\hline $\begin{array}{l}\text { After learning this new } \\
\text { skill, do you think you will } \\
\text { try to help a stranger? }\end{array}$ & Yes (4/4) & No (0/4) & - \\
\hline $\begin{array}{l}\text { After you have learned this } \\
\text { skill, will you show this to } \\
\text { a friend? }\end{array}$ & Yes (4/4) & No (0/4) & - \\
\hline $\begin{array}{l}\text { After today, do you think } \\
\text { you can pack bleeding } \\
\text { wounds on people to stop } \\
\text { the bleeding now? }\end{array}$ & Yes (4/4) & No (0/4) & - \\
\hline $\begin{array}{l}\text { After today, do you think } \\
\text { you can apply a tourniquet } \\
\text { or a made-up tourniquet to } \\
\text { arms and legs to stop the } \\
\text { bleeding? }\end{array}$ & Yes (4/4) & No (0/4) & - \\
\hline
\end{tabular}

Table 2: Post-session $n=4$.

Note: These are the results from the post-session questions asked of the four children. Additional questions asked of two of the pilot group siblings after one month included:

List four things you can stuff into a bleeding wound if someone was bleeding badly.

"I would stuff it with a scarf, socks, a shirt, and a blanket" (7-yearold female).

"I'd call 911, shirt, towel, dish towel, and paper towels" (9-year-old male).

The questions posed to the children were:

- Do you watch the news on television with your family? No $1 /$ Sometimes $1 /$ Yes 2

- Do you think guns are good or bad? Bad 3/ Good 1

- Does your family have guns in your home? Yes 4 
- Do you think you will help someone bleeding when you learn this new skill?

Yes 4

- Why did you take this training?

Two answered: "My mother wanted me to do this" Six-year-old female and nine-year-old male.

One replied: "I think it is important to help people when they get hurt" Seven-year-old female.

One replied: "I want to know that if something happened, that I could save someone" Nine-year-old male.

During the class, the children felt comfortable enough to ask questions to this educator-presenter that were appropriate for their age. The questions were not solicited by the mothers of the children. The post-session survey questions yielded the following data:

- Do you think that this special skill will be useful to you? Yes 4

- After learning this new skill, do you think you will try to help a stranger?

Yes 4

- After you have learned this skill, will you show this to a friend?

Yes 4

- After today, do you think you can pack bleeding wounds on people to stop the bleeding now?

Yes 4

- After today, do you think you can apply a tourniquet or a made-up tourniquet to arms and legs to stop the bleeding? Yes 4

- After one month, the two questions were posed to two of the children seven-year-old female and nine-year-old male (siblings):

List four things you can stuff into a bleeding wound if someone was bleeding badly:

"I would stuff it with a scarf, socks, a shirt, and a blanket".

"I'd call 911, shirt, towel, dish towel, and paper towels".
The post-assessments of the children at two-weeks, one month, and then again at three months offered no negative concerns with the skills taught. The children showed good recollect of the events to stuff a bleeding wound, and how to position a victim, with requests to be instructors one day themselves. It should be noted that the children were more vocal asking questions that developed in their minds.

\section{Conclusion}

More teaching to the pediatric community should be considered and promoted as they are the first ones on the scene. The advantage observed was their quick response to pack wounds, and the agility of their tiny fingers as they packed the wounds in the skill station. Their sincere desire to help a victim was obvious in the questions they posed, and it should be followed up with a PostTraumatic Stress Disorder assessment and a continued spot-check of knowledge for improvisational tourniquets and wound stuffing items. This small pilot opens many doors to future teaching opportunities and the youngest that perhaps this program can be successfully taught to with good skill retention, is no younger than six years of age.

\section{Author Note}

There was no grant funding for this project. This was done as the author's nurse educator fellowship project through the University of North Carolina in the United States of America. IRB was granted through the Invest In Nursing Project of UNC Chapel Hill May 2021.

\section{Conflict of Interest Statement}

There is none to declare.

\section{Bibliography}

1. Butler FK. "Two decades of saving lives on the battlefield: tactical combat casualty care turns 20". Military Medicine 182.3-4 (2017): e1563-e1568.

2. Dhillon NK., et al. "What happens after a stop the bleed class? The contrast between theory and practice". Journal of Surgical Education 76.2 (2019): 446-452.

3. Guiesewite Phillip. "Personal Interview: "How to Determine PTSD signs and symptoms post-STB education" (2021).

4. GunViolenceArchives.org. (n.d.). Active Shooter Statistics (2021). 
5. Inaba K., et al. "Tourniquet use for civilian extremity trauma". Journal of Trauma and Acute Care Surgery 79.2 (2015): 232237.

6. Jacobs LM., et al. "Hartford Consensus: a call to action for THREAT, a medical disaster preparedness concept". Journal of the American College of Surgeons 218.3 (2014): 467-475.

7. Knudson MM., et al. "Response to mass casualty events: from the battlefield to the Stop the Bleed campaign". Trauma Surgery and Acute Care Open 1.1 (2016): e000023.

8. Lei R., et al. "Stop the bleed training empowers learners to act to prevent unnecessary hemorrhagic death". The American Journal of Surgery 217.2 (2019): 368-372.

9. Ramirez M., et al. "Link for Injured Kids: A Patient-Centered Program of Psychological First Aid After Trauma”. Pediatric Emergency Care 33.8 (2017): 532-537.

10. Ross EM., et al. "Stop the bleed: the effect of hemorrhage control education on laypersons' willingness to respond during a traumatic medical emergency". Prehospital and Disaster Medicine 33.2 (2018): 127.

11. Rossaint R., et al. "The STOP the bleeding campaign". Critical Care 17.2 (2013): 1-4.

12. Rzucidlo SE and Campbell M. "Beyond the physical injuries: child and parent coping with medical traumatic stress after pediatric trauma". Journal of Trauma Nursing: the Official Journal of the Society of Trauma Nurses 16.3 (2009): 130-135.

13. Scerbo MH., et al. "The trauma center is too late: Major limb trauma without a pre-hospital tourniquet has increased death from hemorrhagic shock". Journal of Trauma and Acute Care Surgery 83.6 (2017): 1165-1172.

14. Smith AA., et al. "Prehospital tourniquet use in penetrating extremity trauma: Decreased blood transfusions and limb complications". Journal of Trauma and Acute Care Surgery 86.1 (2019): 43-51.

15. Smith ER., et al. "Fatal wounding pattern and causes of potentially preventable death following the pulse night club shooting event". Prehospital Emergency Care 22.6 (2018): 662-668.

16. Zeroeyes.com/statistics. (n.d.). A Collection of Active Shooter and School Shooting Statistics (2021).
17. Zwislewski A., et al. "Practice makes perfect: The impact of Stop the Bleed training on hemorrhage control knowledge, wound packing, and tourniquet application in the workplace". Injury 50.4 (2019): 864-868.

Volume 4 Issue 10 October 2021

(C) All rights are reserved by Kathleen E Jones. 